\title{
Cloning and Characterization of 5-enopy ruvylshikimate-3-phosphate Synthase from Fragaria vesca
}

\section{Feng Liu ${ }^{1}$}

https://orcid.org/0000-0002-0522-6303

\author{
Yingying Ruan ${ }^{2 *}$ \\ https://orcid.org/0000-0002-8521-693X
}

${ }^{1}$ Ningbo City College of Vocational Technology, Department of Horticultural Technology, Ningbo City, Zhejiang Province, China; ${ }^{2}$ Ningbo University, Department of Biotechnology, Ningbo City, Zhejiang Province, China

Editor-in-Chief: Paulo Vitor Farago

Associate Editor: Adriel Ferreira da Fonseca

Received: 2020.05.24; Accepted: 2020.11.13.

${ }^{*}$ Correspondence: coy24@163.com; Tel.: +86-13661552145 (Y.R.)

\section{HIGHLIGHTS}

- The FVEPSPS encodes a polypeptide of 520 amino acids.

- FVEPSPS was constitutively expressed in stems, leaves and roots, with lower expression in roots.

- FVEPSPS expression level could increase significantly with glyphosate treatment.

- Transgenic Arabidopsis Thaliana with FVEPSPS gene exhibited $10 \mathrm{mM}$ glyphosate to resistance.

Abstract: To discover and isolate a glyphosate-resistant gene from Fragaria vesca through gene mining. An open reading frame (ORF) of 1563 bp encoding EPSPSwas amplified from Fragaria vesca (FVEPSPS). FVEPSPS (Genebank: XP004306932.1) encodes a polypeptide of 520 amino acids and it has hightly homologous with EPSPS from other plants. qRT-PCR analysis showed that the FVEPSPS was expressed extensively in all tissues including leaves, roots and stems, with higher expression in leaves. Furthermore, transgenic Arabidopsis Thaliana exhibited $10 \mathrm{mM}$ glyphosate to resistance. Therefore, this research offers a new glyphosate-resistant gene for development of transgenic crops.

Keywords: Fragaria vesca; FvEPSPS; glyphosate; transformation; Arabidopsis Thaliana.

\section{INTRODUCTION}

5-Enolpyruvylshikimate-3-phosphate synthase (EPSPS) is a key enzyme in aromatic amino acid synthesis pathway [1]. Because the target enzyme of glyphosate inhibition is EPSPS, this enzyme is widely studied in glyphosate resistant plants. Herbicide glyphosate inhibits EPSPS reaction and causes plant death, so it also kills food crops by its non-selective feature [2,3]. The $80 \%$ of commercial glyphosate-resistant GM crops are related to EPSPS.

The application of EPSPS gene in the transgenic glyphosate resistant crops is mainly used through overproduction of the wild-type EPSPS or expression of mutant EPSPS with glyphosate resistance [4-7]. Since the EPSPS gene plays an important role in increasing herbicide resistance, much studies have been 
carried out to understand glyphosate resistance of EPSPS [8-10]. Until now, EPSPS gene has been cloned from from bacteria, fungi, herb plants and wood plants [11-13]. Today, there is a great interest in finding glyphosate tolerant genes for GM crops.

Although EPSPS gene has been isolated in many plant species, it has never been cloned from Fragaria vesca. A naturally glyphosate-resistant Fragaria vesca was found in Shanghai, China, whereas its mechanism of resistance to glyphosate is still unknown. In this experiment, the open reading frame encoding the enzyme FvEPSPS was cloned and the sequence was identified for the first time. The potential glyphosate resistance mechanism of FVEPSPS was also investigated.

\section{MATERIAL AND METHODS}

\section{Seed source}

The Fragaria vesca seeds were collected from Shanghai Jiaotong University, Shanghai, China. Young leaves were used as the starting material for RNA isolation.

\section{Cloning and sequence analysis FvEPSPS gene}

cDNA from Fragaria vesca as template amplified putative FVEPSPS gene. The PCR production that inserted into PMD-18 vector was sequenced. The PCR products linked to PMD-18 vector and sequenced. The sequence comparison was observed through NCBI database. MEGA 5.0 software was used to built the phylogenetic tree. The primers are listed in Table 1.

\section{Quantitative real-time RT-PCR}

According to a previous report, the FVEPSPS gene expression used to be observed by qRT-PCR analysis. Transcriptional level expression of FVEPSPS were used in different tissues of Fragaria vesca, including leaves, stems and roots at 30-day-old seedlings, respectively. A 18SrRNA gene was used as housekeeping gene. $10 \mathrm{mM}$ glyphosate was sprayed on Fragaria vesca, and the leaves were harvested at different hours $(12,24,36$ and $48 \mathrm{~h})$. The expression level of $F v E P S P S$ gene was calculated by $2^{-\Delta \Delta t}$ method. The qRT-PCR primers are listed in Table 1.

Table 1. Primers used in study

\begin{tabular}{lll}
\hline Primer name & \multicolumn{1}{c}{ Sequence $\left(5^{\prime}-3^{\prime}\right)$} & \multicolumn{1}{c}{ Purpose of primers } \\
\hline FvEPSPS-1 & ATGGCCCAAGTGAGCAAAATCTGC & Amplify the FvEPSPS \\
FvEPSPS-2 & TTAATGTTTTGTAAACTTCCCAAGG & Amplify the FvEPSPS for \\
FvEPSPS-3 & CCCATATGATGGCCCAAGTGAGCAAAAT & prokaryotic expression vector \\
FvEPSPS-4 & CCTCGAGTTAATGTTTGTAAACTTCCCA & Amplify the signal peptide \\
TSP-1 & CCCAAGCTTATGGCTCAAGTTAGCAGAATCTGC & Amplify the FvEPSPS for \\
TSP-2 & GAGTACTCATGACCTTAAGAGGACGAAGC & eukaryotic expression vector \\
FvEPSPS-5 & GAGTACTATGGCCCAAGTGAGCAAAATC & qRT-PCR analysis of 18SrRNA \\
FvEPSPS-6 & GCTCAGATTAATGTTTTGTAAACTTCCC & \\
18 SrRNA-f & AGAAACGGCTACCACATC & qRT-PCR analysis of FvEPSPS \\
$18 S r R N A-r$ & CCATCCCAAAGTCCAAC & \\
qFvEPSPS-f & GCCGTTGACTGCTGCAGTAACTG & \\
qFvEPSPS-r & TTCAACATCTCCCAGAGCCAAAG &
\end{tabular}

\section{In vitro glyphosate sensitivity assays}

cDNA fragment encoding the protein of FvEPSPS was amplified by PCR. The amplified fragment of FvEPSPS gene was digestion by using $\mathrm{Ndel}$ and $\mathrm{Xhol}$ and inserted into pET-28a prokaryotic vector to establish recombinant plasmids pET-FvEPSPS. ER2799 containing either pET-FvEPSPS or pET-28a was grown by shaking in liquid M9 minimal medium at $37^{\circ} \mathrm{C}$. The medium add to different concentration of glyphosate ranging from 0-100 mM. The cell growth densities were tested by spectrophotometry at $600 \mathrm{~nm}$. The primers are listed in Table 1. 


\section{Construction of the plant expression vector with FvEPSPS}

The method of plant vector construction follows the previous report [13]. In order to located in chloroplast, the DNA fragment encoding the chloroplast transit peptide of Arabidopsis (TSP) was connection with the front of the FVEPSPS. The recombinant plasmid was introduced into A. tumefaciens $\mathrm{EH} 105$ by electroporation. The method for genetic transformation of Arabidopsis thaliana was by Agrobacterium-mediated transformation. The primers are listed in Table1.

\section{Arabidopsis Thaliana transformation}

The floral-dipping method of Arabidopsis Thaliana follows according to previous reports. $T_{0}$ generation seeds of the transgenic Arabidopsis Thaliana were selected on 1/2 MS solid medium with $40 \mathrm{mg} \mathrm{L}^{-1}$ hygromycin. $T_{2}$ generation plants of hygromycin resistance confirmed by RT-PCR and harvested for further research.

\section{Analysis of glyphosate resistance in transgenic $A$. thaliana}

To test root length of $A$. thaliana, the $\mathrm{T}_{2}$ Sterilized $A$. thaliana seeds were grown on $1 / 2 \mathrm{MS}$ solid medium containing glyphosate $(0,300,500$, and $800 \mu \mathrm{M})$. After grown for ten days, the root length was surveyed. The $A$. thaliana transformants were grown in sterile culture and then transferred to soil in the greenhouse. Spraying with $10 \mathrm{mM}$ glyphosate on plants at 40-day-old. The spray tests were observed after six days.

\section{RESULTS}

\section{Cloning and sequence analysis of FVEPSPS}

A 1563 bp sequence (named FVEPSPS) was obtained by PCR. Sequence analysis showed that the FVEPSPS gene contained an ORF of 1563 bp (Genebank: XP004306932.1), which encodes a polypeptide of 520 amino acids. FvEPSPS protein had one EPSPS conserved sequence. The amino acid homology analysis indicated that FvEPSPS belongs to Class I EPSPS (Figure 1a). The evolution tree indicated that FvEPSPS is most similar to Rosa Chinensis (Figure 1b). 
a

\begin{tabular}{|c|c|c|}
\hline VEPSPS & MAQVSRICSNGAÇSFNLLFNVSRPQIPRSINSISLKSQFLGSSNSLSLKRESGFVGRVRAGGLRVSASVVIAEKPSTVPE & 80 \\
\hline E.coli-EPSPS & ${ }_{n-1, \cdots}$ & 0 \\
\hline CP4-EPSPS & $\cdots \cdots$ & \\
\hline FVEPSPS & IVLCP IREISGTITLPGSRSISNRILLIAALSEGTTVVDNLLDSDD INYML GALRTLGLNVEDDRANKHAVVEGCEGGCFP & 160 \\
\hline E.coli-EPSPS & 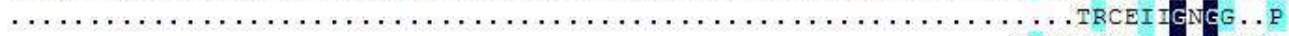 & 11 \\
\hline CP4-EPSPS & 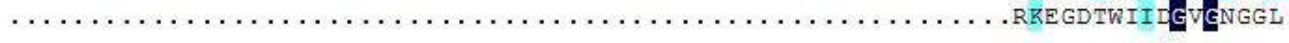 & 17 \\
\hline FUEPSPS & VTGIRCLEADVDCELGTDQFF & 24 \\
\hline E.COli-EPSPS & CAIRIGGARITYLEQENYPFLRLDE. . & 85 \\
\hline CP4-EPSPS & LRVLNAIREMG Q $Q$ QVRSE DGDRIE. & 8. \\
\hline FVEPSPS & FIALGDVEVE I IDKL IS IPYVEMTIKLMERFGVTVEHSDSWDRELVRGGRYKSP & 32 \\
\hline E.coli-EPSPS & GET GGNVDVDGSVSSOFLIALIMTAEI APEDTVIRIRGDLVSRPYIDITINLMRTFGVEIEN . QHY CQEVVRGGQSYCSP & 164 \\
\hline CP4-EPSPS & PRTPTPITYRVPUA A & 166 \\
\hline FVEPSPS & VIGGTV̈TVEGCGTSSIQGDVREAEVIERMGZEVTWTENSVTVTG.PQRHSSGRKFLRAV & 398 \\
\hline .coli-EPSPS & VKVTGIGRNSMQGDIREADVIEKMGATICWGDDYISCT $\ldots \ldots \ldots$ RGEINAI & 23 \\
\hline CP4-EPSPS & 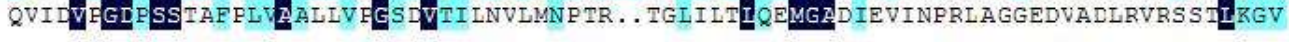 & 244 \\
\hline FvEPSPS & EATVEEGPYCIITP. EE. & 4 \\
\hline E.coli-EPSPS & RKVGAEVEEGHDY IRITP. FE. & 30 \\
\hline CP4-EPSPS & GIRLNGVDCDEGETSLVVRGREDGKGIGNAS & 32 \\
\hline FVEPSPS & ACG.DVPVII KDFGCTRKTEFNYEVLG & 52 \\
\hline .coli-EPSPS & NDHRU AUCESLVALS.DTEVIIIDERCTARTERDYFECLA & 35 \\
\hline CP4-EPSPS & 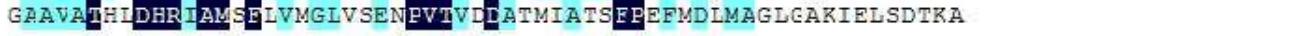 & 38 \\
\hline
\end{tabular}

$\mathrm{b}$

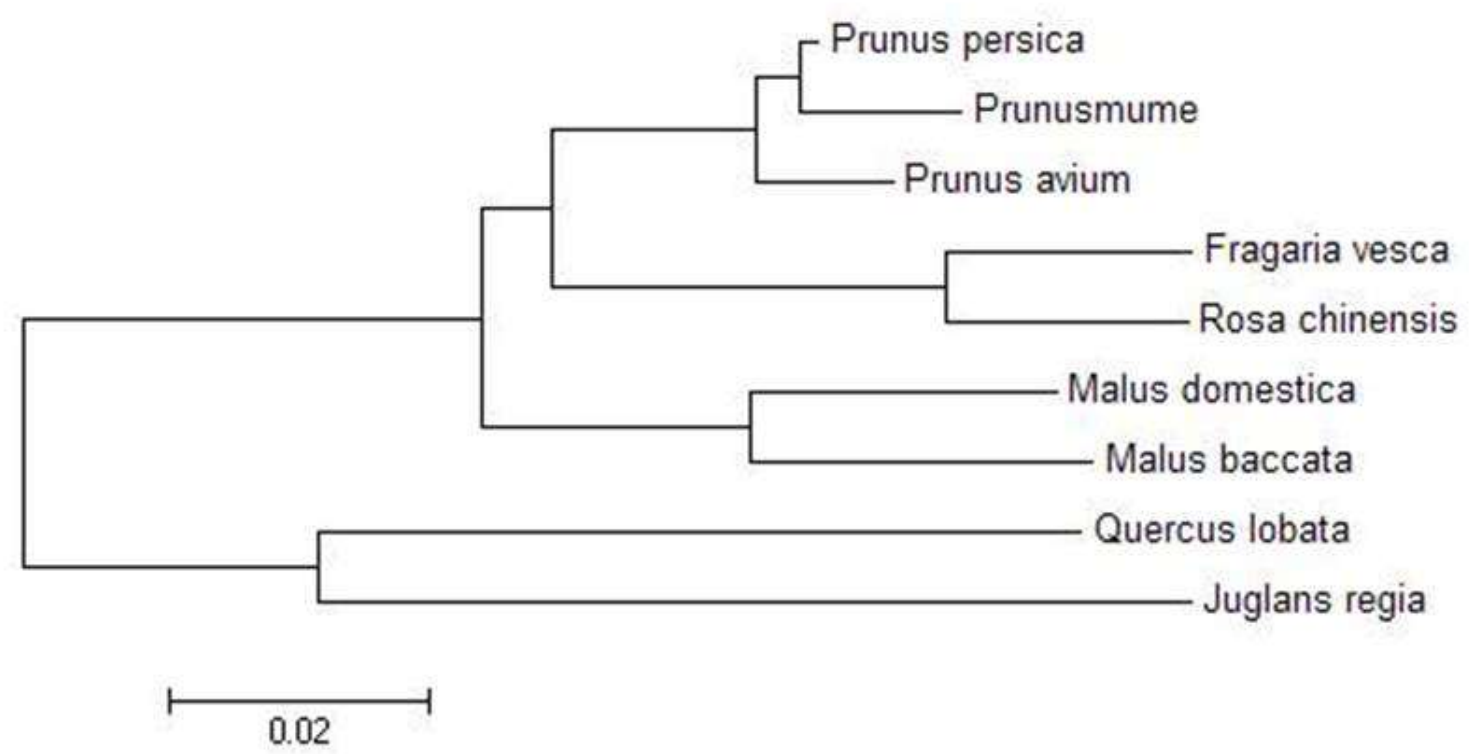

Figure 1. (a) Multiple alignments of deduced amino acid sequence of FvEPSPS with other known plant EPSPS genes. Three EPSPS proteins were Fragaria vesca (FvEPSPS, XP004306932.1), Escherichia coli (E.coli-EPSPS, P07638) and Agrobacterium tumefaciens CP4 (CP-EPSPS, Q9R4E4). (b) Phylogenetic analysis of FvEPSPS protein orthologs. Sources of the orthologous proteins were indicated in parenthesis. The numbers on the branches represent bootstrap support for 1,000 replicates.

\section{Expression pattern analysis of FVEPSPS gene}

The expression of different tissues was also detected at the transcription level. It was found that the expression level of FVEPSPS gene was highest in the leaves, while the expression level in the stems and roots was relatively low (Figure 2). The expression of target gene in the leaves of Fragaria vesca was analyzed by qRT-PCR during different time periods after spraying glyphosate treatment. The expression of 
the FVEPSPS gene increased at the level of transcription after treatment, and the expression of the FVEPSPS had risen more three-fold after $24 \mathrm{~h}$ (Figure 3).

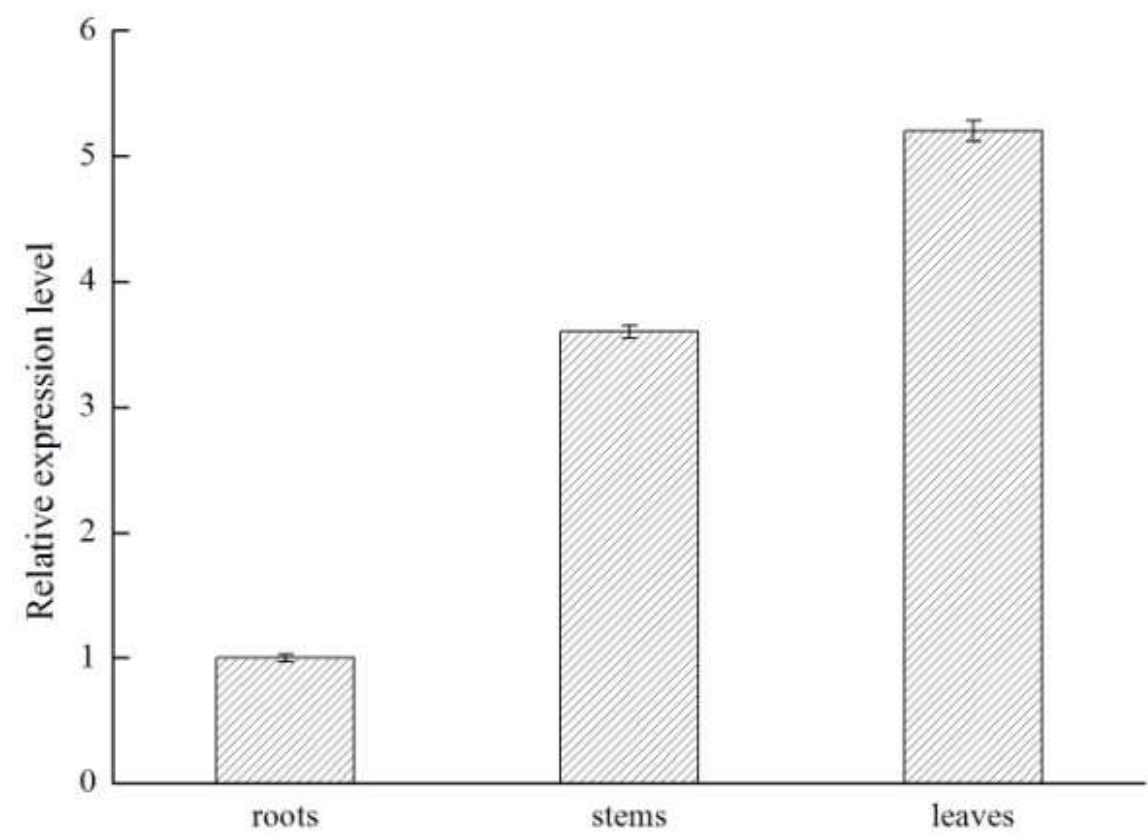

Figure 2. The expression of FVEPSPS in different tissues.

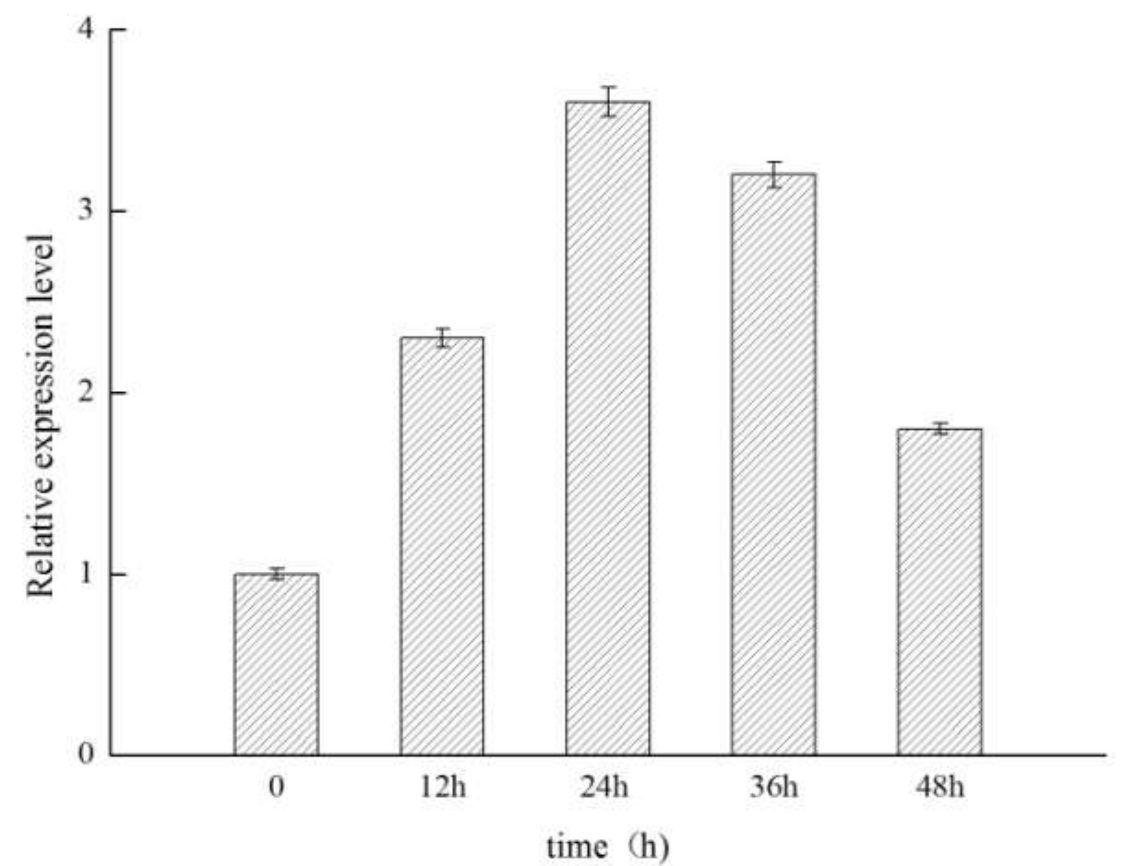

Figure 3. mRNA level of the FvEPSPS after glyphosate treatment.

\section{Growth of cells in the presence of glyphosate}

The growth curves of the ER2799 cells are shown in Figure 4. After $36 \mathrm{~h}$ of incubation, the results indicated that all cells were well without glyphosate, while under the condition of $75 \mathrm{mM}$ glyphosate, the growth of cells and cells containing pET-28a were severely limited. However, the ER2799 cells containing pET-EPSPS could grew well, but the cells containing pET-FvEPSPS was entirely suppressed in $100 \mathrm{mM}$ glyphosate. 


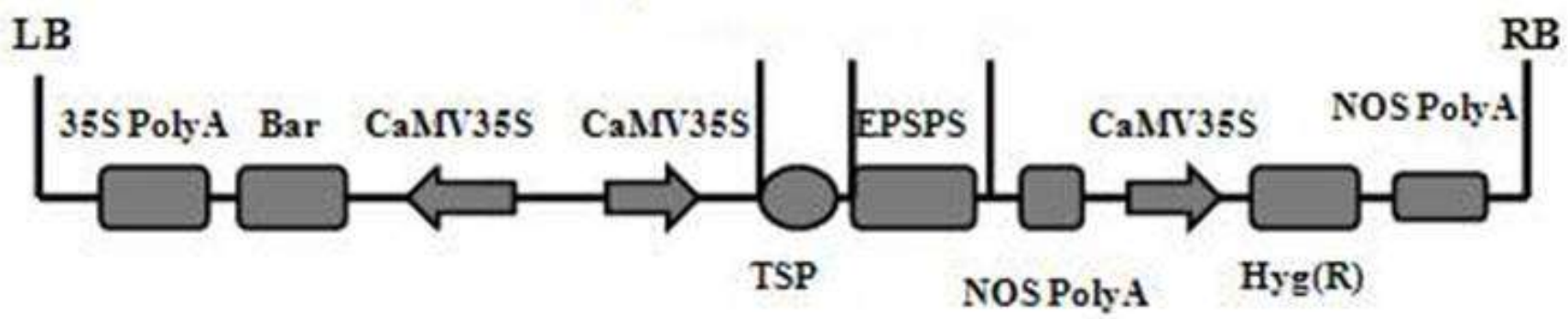

Figure 4. Growth of the E. coli EPSPS mutant ER2799 harboring either PET-28a, pET-FvEPSPS in a liquid M9 minimal medium supplemented with various concentrations of glyphosate.

\section{Glyphosate tolerance in transgenic Arabidopsis thaliana}

Construction of the plant expression vector with FVEPSPS was used to infect Arabidopsis (Figure 5). RT-PCR analysis showed that FVEPSPS expressed in three transgenic $\mathrm{T}_{2}$ lines (Figure 6). One line was selected to analyze resistance to glyphosate with wild type as controls. Glyphosate affects plant root growth. Under the action of glyphosate, the root system grew weakly. As shown in Figure 7, the results showed that transgenic plants overexpressing FVEPSPS gene were able to grow with $800 \mu \mathrm{M}$ glyphosate, whereas wildtype plants were strongly inhibited with $300 \mu \mathrm{M}$ glyphosate. In addition, all transgenic lines showed more tolerance to glyphosate (Figure 8). The leaves of the wild-type appeared yellow and eventually died with spray $10 \mathrm{mM}$ glyphosate after six days, while the transgenic plants continued to grow well. The results also indicated that the transgenic Arabidopsis thaliana with overexpression of FVEPSPS had higher glyphosate resistance than the wild type.
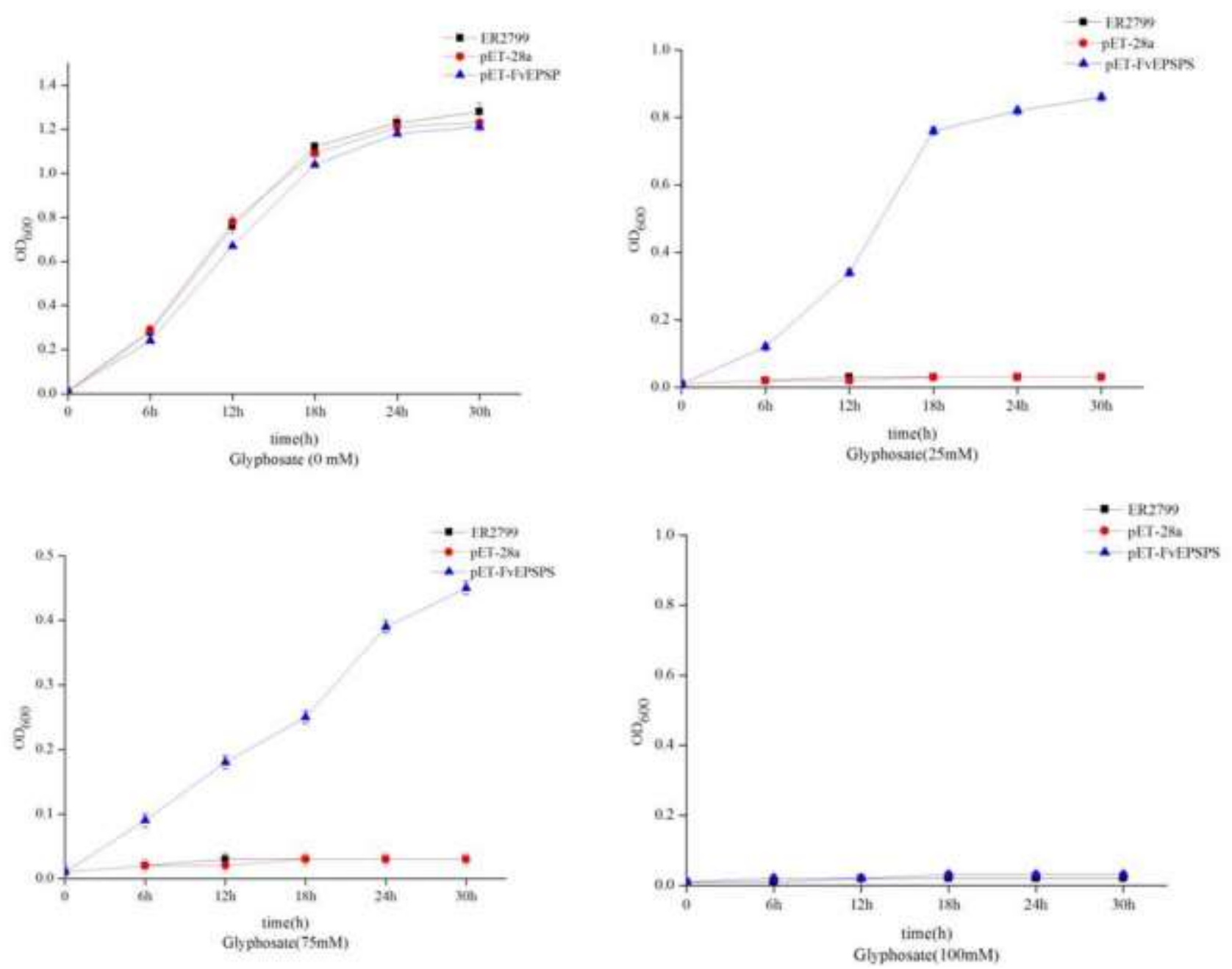

Figure 5. The plant expression vector with FvEPSPS. 


\section{WT \\ M1 \\ $\mathrm{M} 2$ \\ M3}

\section{Target gene}

\section{SrRNAgene}

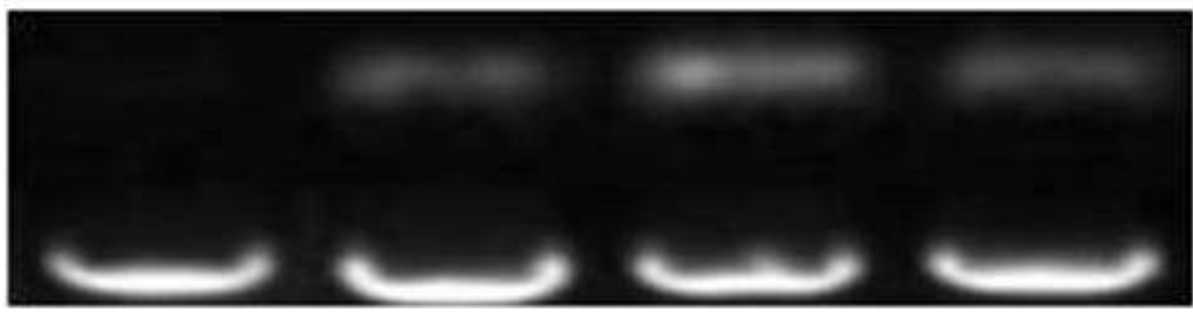

Figure 6. Expression analysis of three transgenic lines by RT-PCR. WT: non-transgenic plant; M1-M3: three putative transgenic lines.

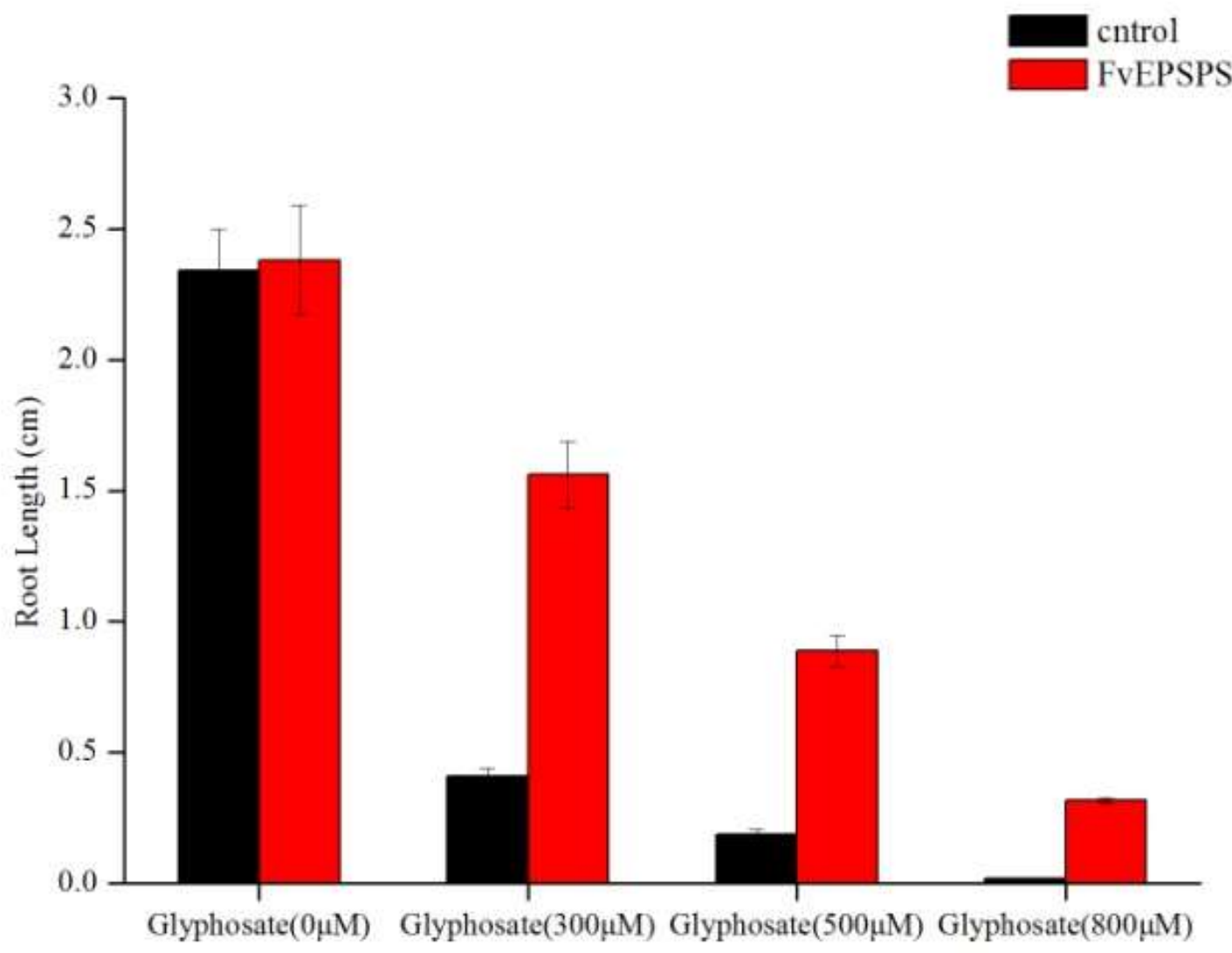

Figure 7. Root growth development of the transgenic plants under glyphosate stress.

A

$\mathrm{B}$
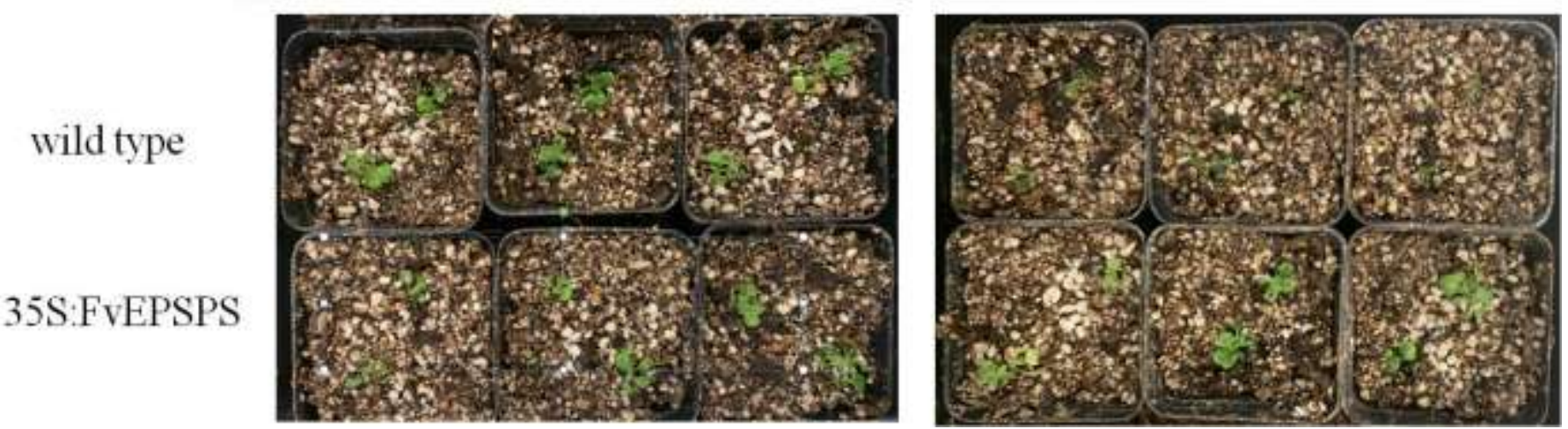

Figure 8. Photographs of Arabidopsis thaliana sprayed with $10 \mathrm{mM}$ glyphosate. (A) Photograph taken before the spraying treatment. (B) Photograph taken 6 days after the spraying treatment. 


\section{DISCUSSION}

Although Fragaria vesca is widespread in natural environment, there have been no previous reports of glyphosate resistance in Fragaria vesca. To our knowledge, this is the first report on the cloning and identification of EPSPS from Fragaria vesca.

Glyphosate efficiently restrains EPSPS by preventing the synthesis of aromatic amino acids, leading to plant death [14]. EPSPS gene has different transcription level in plant tissues [4]. The transcription level indicated that it is extensive for the expression of the FvEPSPS gene, which is expressed in roots, stems, and leaves, and the leaf is the most highly expressed tissue. This transcription level pattern is in the same as Field bindweed and Camptotheca acuminata [15,16]. Spraying $10 \mathrm{mM}$ glyphosate after $36 \mathrm{~h}$, transcription expression level of FVEPSPS is higher than the control group. The result is the same in field bindweed. These illustrated that the EPSPS played a key role in the reaction to glyphosate.

According to report, the amplification of EPSPS gene could enhanced plant resistance to the glyphosate . The petunia cells enhanced glyphosate to tolerance by overexpression wild-type EPSPS gene. In our study, the transgenic plants with FVEPSPS gene survive on $10 \mathrm{mM}$ of glyphosate. These results indicated that FVEPSPS gene could improve the tolerance of transgenic plants to glyphosate. In the previous studies, the transgenic tobacco plants is $5 \mathrm{mM}$ glyphosate to tolerance [17], while transgenic FVEPSPS Arabidopsis thaliana. is $10 \mathrm{mM}$ glyphosate to tolerance. Therefore, this research offers a new glyphosate-resistant gene for development of transgenic crops.

Funding: This research was funded by foundation of Ningbo City College of Vocational Technology, grant number ZZX18123.

Conflicts of Interest: "The authors declare no conflict of interest." "The funders had no role in the design of the study; in the collection, analyses, or interpretation of data; in the writing of the manuscript, or in the decision to publish the results".

\section{REFERENCES}

1. Herrmann KM. The shikimate pathway: early steps in the biosynthesis of aromatic compounds. Plant Cell 1995 Jan:907-19.

2. Cao G, Liu Y, Zhang S, Yang X. A novel 5-enolpyruvylshikimate-3-phosphate synthase shows high glyphosate tolerance in Escherichia coli and tobacco plants. PLoS One. 2012 Mar;7:318-29.

3. Gao Y, Tao B, Qiu L.Role of physiological mechanisms and EPSPS gene expression in glyphosate resistance in wild soybeans (Glycine soja). Pestic Biochem Physiol.2014 Sep;109:6-11.

4. He M, Yang ZY, Nie YF. A new type of class I bacterial 5-en0opyruvylshikimate-3-phosphate synthase mutants with enhanced tolerance to glyphosate. Biochim Biophys Acta Gen Subj. 2001 Feb;68:1-6.

5. Liang A, Sha J, Lu W. A single residue mutation of 5-enoylpyruvylshikimate-3- phosphate synthase in Pseudomonas stutzeri enhances resistance to the herbicide glyphosate. Biotechnol Lett. 2008 Jan;30:1397-401.

6. Liu F, Cao YP. Cloning and characterization of 5-enopyruvylshikimate-3- phosphate synthase from Pantoea sp. GMR. 2015 Mar; 14:19233-41.

7. Yi SY, Cui Y, Zhao Y. A Novel Naturally Occurring Class I 5-Enolpyruvylshikimate-3-Phosphate Synthase from Janibacter sp. Confers High Glyphosate Tolerance to Rice. Sci Rep. 2016 Mar; 6:191-14.

8. Duke SO, Powles SB. Glyphosate: a once-in-a-century herbicide. Pest Manage Sci. 2008 Oct; 64:319-25.

9. Tian YS, Xu J, Han J. Complementary screening, identification and application of a novel class II 5enopyruvylshikimate -3-phosphate synthase from Bacillus cereus. World J. Microbiol Biotechnol. 2013 Sep; 29:54957.

10. Han J, Tian YS, Xu J, Wang LJ. Functional characterization of aroA from Rhizobium leguminosarum with significant glyphosate tolerance in transgenic Arabidopsis. J Microbiol Biotechnol.2014 Mar; 24:1162-9.

11. Baerson SR, Rodriguez DJ, Tran M, Feng Y. Glyphosate-resistant goosegrass. Identification of a mutation in the target enzyme 5-enolpyruvylshikimate-3-phosphate synthase. Plant Physiol. 2002 Oct; 129:1265-75.

12. Huang ZF, Zhang CX, Huang HJ. Molecular cloning and characterization of 5-enolpyruvylshikimate -3-phosphate synthase gene from Convolvulus arvensis L. Mol Biol Rep. 2014 Sep;41:2077-84.

13. Liu F, Cao YP. Expression of a bacterial aroA gene confers tolerance to glyphosate in tobacco plants. Turk J Biol. 2018 Aug;42:187-94.

14. Liu F, Cao YP. Expression of the 5-enoylpyruvylshikimate-3-phosphate synthase domain from the Acremonium sp. aroM complex enhances resistance to glyphosate. Biotechnol Lett. 2018 Feb;40:855-64.

15. Binarová $P$, Cvikrová $M$, Havlický $T$. Changes of shikimate pathway in glyphosate tolerant alfalfa cell lines with reduced embryogenic ability. Biol. Plant. 1994 Mar;36:65-73. 
16. Gong Y, Liao Z, Chen M. Characterization of 5-enolpyruvylshikimate-3-phosphate synthase gene from Camptotheca acuminata. Biol. Plant. 2014 Feb;50:542-50.

17. Peng RH, Tian YS, Xiong AS. A novel 5-enolpyruvylshikimate-3-phosphate synthase from Rahnella aquatilis with significantly reduced glyphosate sensitivity. PloS. One.2012 Oct;7(8):36-42.

(C) 2021 by the authors. Submitted for possible open access publication under the terms and (c) (5) 8 (o) 2021 by the authors. Submitted for possible open access publication under the terms and
conditions of the Creative Commons Attribution (CC BY NC) license
(https://creativecommons.org/licenses/by-nc/4.0/). 